\title{
Computational Probing of Tin-based Lead-free Perovskite Solar Cells: Effects of Absorber Parameters and Various ETL Materials on Device Performance
}

\author{
Arunkumar Prabhakaran Shyma \\ Vellore Institute of Technology: VIT University \\ Raja Sellappan ( $\square$ raja.sellappan@vit.ac.in ) \\ Vellore Institute of Technology: VIT University https://orcid.org/0000-0002-9837-0872
}

\section{Research Article}

Keywords: Tin based Perovskite solar cell, Lead toxicity, Numerical analysis, Absorber layer, Quantum efficiency, Defect density, ETL materials

Posted Date: July 1st, 2021

DOl: https://doi.org/10.21203/rs.3.rs-658718/v1

License: (c) (i) This work is licensed under a Creative Commons Attribution 4.0 International License. Read Full License 


\title{
Computational probing of Tin-based Lead-free perovskite solar cells: Effects of Absorber parameters and various ETL materials on device performance
}

\author{
Arunkumar Prabhakaran Shyma ${ }^{\mathrm{a}}$ and Raja Sellappan*b \\ ${ }^{a}$ Department of Physics, School of Advanced Sciences, Vellore Institute of Technology, \\ Vellore 632014, India \\ ${ }^{b}$ Centre for Nanotechnology Research, Vellore Institute of Technology, Vellore, 632014, \\ India
}

\begin{abstract}
Tin-based perovskite solar cells have gained global research attention due to the lead toxicity and health risk associated with its lead-based analogue. The promising optoelectrical properties of the Tin-based perovskite have attracted researchers to work on developing solar cells with higher efficiencies comparable to Lead-based analogues. Tin-based perovskites outperform the lead-based ones in areas like optimal band gap and carrier mobility. A detailed understanding regarding the effects of each parameters and working conditions on Tin-based perovskite is crucial in order to improve the efficiency. In the present work, we have carried out a numerical simulation of planar heterojunction Tin-based $\left(\mathrm{CH}_{3} \mathrm{NH}_{3} \mathrm{SnI}_{3}\right)$ perovskite solar cell employing SCAPS 1D simulator. Device parameters namely thickness of the absorber layer, defect density of the absorber layer, working temperature, series resistance, metal work function have been exclusively investigated. $\mathrm{ZnO}$ has been employed as the ETL (Electron transport layer) material in the initial simulation to obtain optimized parameters and attained a maximum efficiency of $19.62 \%$ with $1.1089 \mathrm{~V}$ open circuit potential $\left(\mathrm{V}_{\mathrm{oc}}\right)$ at 700 $\mathrm{nm}$ thickness (absorber layer). Further, different ETL materials have been introduced into the optimized device architecture and $\mathrm{Zn}_{2} \mathrm{SnO}_{4}$ based device delivers an efficiency of $24.3 \%$ with a $\mathrm{V}_{\mathrm{oc}}$ of $1.1857 \mathrm{~V}$. The obtained results indicate a strong possibility to model and construct better performing perovskite solar cells based on Tin (Sn) with $\mathrm{Zn}_{2} \mathrm{SnO}_{4}$ as ETL layer.
\end{abstract}

Keywords: Tin based Perovskite solar cell; Lead toxicity; Numerical analysis; Absorber layer; Quantum efficiency; Defect density; ETL materials

*Corresponding author

Centre for Nanotechnology Research, Vellore Institute of Technology, Vellore, 632014, India E-mail address: raja.sellappan@vit.ac.in (Raja Sellappan). 


\section{Introduction}

In recent times, Perovskite solar cells based on organometallic halides have gained significant amount of attention due to their opto-electronic properties and low manufacturing costs. The quantum leap in terms of efficiency in perovskite based solar cells (PSCs) from 3.8 $\%$ to $25.2 \%$ makes it further intriguing yet challenging [1-7]. This remarkable performance of PSCs can be ascribed to the distinctive $\mathrm{ABX}_{3}$ crystal structure of perovskite that consists of a monovalent organic or inorganic cation (A), divalent cation (B) and monovalent anion (X) which delivers exceptional photovoltaic characteristics including intense light absorption, ample ambipolar charge mobility and minimal exciton binding energy $(<25 \mathrm{meV})[8,9]$.

On the other hand, the main charm behind the performance of organometal halide perovskite is attributed to the role played by $\mathrm{Pb} \mathrm{[10].} \mathrm{Pb}$-based perovskite solar cells loses its charm when coming to the water solubility of lead which leads to severe health risks and environmental issues [11]. World health organisation (WHO) has recently enlisted $\mathrm{Pb}$ as one among the ten most toxic materials with respect to human health and initiated strict measures to lessen the usage of $\mathrm{Pb}[12,13]$. The health hazards regarding the usage of $\mathrm{Pb}$ drove the global research community to explore lead free perovskite structures. Elements which possess a +2 oxidation state are considered as viable alternatives for lead free halide perovskite structure. A large number of materials can be considered in this manner. Many of the materials were tried and found not to implement in the perovskite structure since it possess large band gap $\left(\mathrm{Be}^{2+}\right.$, $\left.\mathrm{Ca}^{2+}, \mathrm{Sr}^{2+}, \mathrm{Ba}^{2+}\right)$ and toxicity $\left(\mathrm{Cd}^{2+}, \mathrm{Hg}^{2+}\right)$ [14]. Tin-based perovskites are found to be the best alternative to $\mathrm{Pb}$ since it possesses an optical bandgap in the range of 1.2 to $1.5 \mathrm{eV}$ which satisfies the Shockley-Queisser Limit $(\sim 1.3 \mathrm{eV})$. This ideal band gap expedited the development of $\mathrm{Pb}$-free Tin-based perovskite solar cells [15]. The low bimolecular constant to mobility ratio of Tin-based perovskites also provides the basis of replacement since it exhibits similar ratio with the $\mathrm{Pb}$ containing counterparts [16]. The comparability of Tin-based perovskites to the $\mathrm{Pb}$ containing counterparts have gained significant research attention in the field of perovskite solar cells as a viable alternative for the future.

Recently, many efforts have been made to improve the performance of $\mathrm{Pb}$-free perovskite solar cells such as compositional and band gap engineering. In spite of the developments in the performance enhancements, the overall efficiency (PCE) of the device is limited due to external as well as internal parameters. In this regard, the simulation of these devices are crucial to understand the correlation between device parameters and the cell 
performance. The main motive behind this present research work is to simulate and optimise the device parameters for the optimum efficiency of $\mathrm{Pb}$-free perovskite solar cells. In order to obtain this, SCAPS 1D simulator is employed to examine the different device parameters such as absorber layer thickness, working temperature, quantum efficiency and series resistance, etc. SCAPS 1D is a numerical simulation program developed at the Department of Electronics and Information Systems of the University of Gent, Belgium. The basic equations employed in the numerical simulation are Poisson equation $(E q 1)$, hole $(E q 2)$ and electron continuity $(E q 3)$ equations as follows.

$$
\begin{aligned}
& \frac{d}{d x}\left(-\varepsilon(x) \frac{d \psi}{d x}\right)=q\left[p(x)-n(x)+N_{d^{+}}(x)-N_{a^{-}}(x)+p_{t}(x)-n_{t}(x)\right] \\
& \frac{d p_{n}}{d t}=G_{p}-\frac{p_{n}-p_{n o}}{\tau_{p}}-p_{n} \mu_{p} \frac{d \xi}{d x}-\mu_{p} \xi p \frac{d p_{n}}{d x}+D_{p} \frac{d^{2} p_{n}}{d x^{2}} \\
& \frac{d n_{p}}{d t}=G_{n}-\frac{n_{p}-n_{p o}}{\tau_{n}}-n_{p} \mu_{n} \frac{d \xi}{d x}-\mu_{n} \xi \frac{d n_{p}}{d x}+D_{n} \frac{d^{2} n_{p}}{d x^{2}}
\end{aligned}
$$

Here, $D$ stands for diffusion coefficient, $\psi$ represents electrostatic potential, $G$ defines the generation rate and $\varepsilon$ is the permittivity. $p, n, p_{t}, n_{t}$ represents free holes, free electrons, trapped holes and trapped electrons respectively. $N_{a}^{-}$and $N_{d}^{+}$stands for ionized acceptor doping concentration as well as ionized donor concentration, respectively [17].

\section{Device modelling and simulation}

Currently, research community has shown a significant interest in theoretical studies and modelling of perovskite solar cells [18-21]. The device architecture and energy band diagram of the proposed perovskite solar cell are depicted in figure 1. Herein, we have proposed a Tin-based perovskite solar cell which consists of five main layers. Spiro-OMeTAD was employed as Hole transport layer (HTL) for all studies. ZnO was used as Electron transport material (ETL) for initial simulation to obtain optimized parameters for the device. Further, a detailed comparison between different ETL materials were also conducted to find the best suited ETL for Pb-free perovskite solar cell. A n-i-p planar architecture was considered in which the absorber layer is sandwiched between ETL and HTM. Thermal velocities of hole and electron were kept as $1 \times 10^{7} \mathrm{~cm} \mathrm{~s}^{-1}$. All the simulations were conducted under an air mass of AM $1.5 \mathrm{G}$ and an illumination of $1000 \mathrm{~W} \mathrm{~m}^{-2}$. The operating temperature was varied from 
300 to $370 \mathrm{~K}$ in order to obtain the optimum working conditions. Device and material parameters that were used for the simulation are acquired from previous literatures and theories [22-25]. The parameters employed in the simulation are summarized in table 1 and 2 . We have separately carried out the simulation for each metal back contact to find the best performance (figure 3). Among the simulated results, device employed with $\mathrm{Ni}$ and Pt has exhibited better power conversion efficiency compared to other metal contacts. We have fixed $\mathrm{Ni}$ as the back contact considering the cost effectiveness of $\mathrm{Ni}$ compared to Pt. The simulated device performance for each back contact is given in Table 3. We have tuned and further enhanced the device performance employing the optimum values of various parameters obtained through numerical simulation such as open circuit voltage $\left(\mathrm{V}_{\mathrm{oc}}\right)$, Short circuit current $\left(\mathrm{J}_{\mathrm{sc}}\right)$, Fill factor, and power conversion efficiency (PCE).
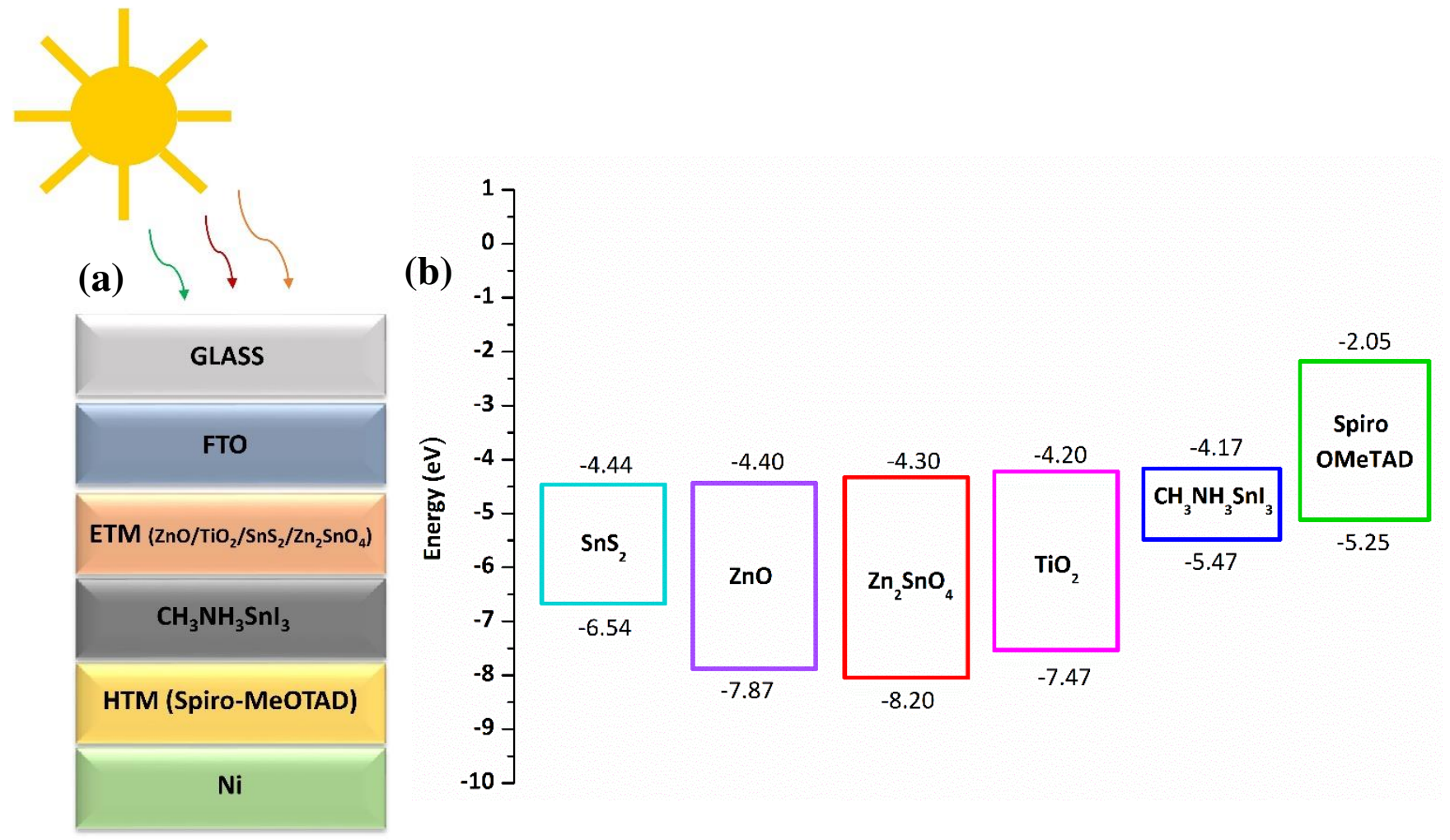

Figure 1. (a) Device architecture of the Tin-based perovskite solar cell and (b) Energy band alignment for the proposed devices

The equivalent circuit of solar cell under the light illumination is shown in figure 2 . The perovskite absorber layer generates electron and hole pairs once the light is illuminated and develops a voltage across the device. Photocurrent is produced within the device as a result of the movement of electron and holes. The photocurrent is directly proportional to the illumination rate and additionally depends on the size of the surface area being illuminated. Here, $V_{\text {oc }}$ is also a function of illumination. 


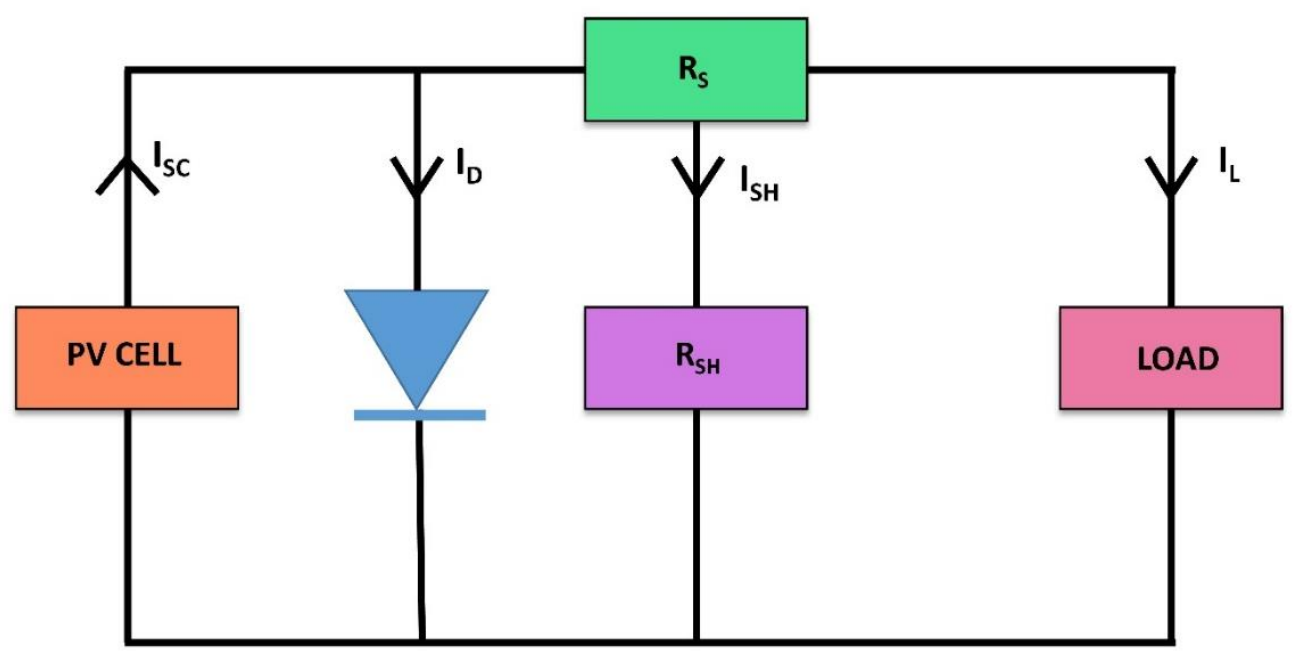

Figure 2. Equivalent electrical circuit diagram for a solar cell under illumination

Table 1. Parameters used to run the simulation of Tin-based perovskite solar cells

\begin{tabular}{|c|c|c|c|c|c|c|}
\hline Parameters & $\mathrm{ZnO}$ & $\mathrm{TiO}_{2}$ & $\mathrm{SnS}_{2}$ & $\mathrm{Zn}_{2} \mathrm{SnO}_{4}$ & $\mathrm{CH}_{3} \mathrm{NH}_{3} \mathrm{SnI}_{3}$ & $\begin{array}{c}\text { Spiro } \\
\text { OMeTAD }\end{array}$ \\
\hline Thickness (nm) & 100 & 100 & 100 & 100 & $100-1400$ & 100 \\
\hline Bandgap (eV) & 3.4 & 3 & 2.24 & 3.35 & 1.30 & 3.2 \\
\hline $\begin{array}{l}\text { Electron affinity } \\
(\mathrm{eV})\end{array}$ & 4.3 & 4 & 4.24 & 4.5 & 4.2 & 2.1 \\
\hline $\begin{array}{c}\text { Dielectric } \\
\text { permittivity }\end{array}$ & 9 & 9 & 10 & 9 & 10 & 3 \\
\hline $\begin{array}{c}\text { CB Effective } \\
\text { density of states } \\
\left(1 / \mathrm{cm}^{3}\right)\end{array}$ & $2 E+18$ & $2.2 E+18$ & $2.2 E+18$ & $2.2 E+18$ & $1 E+18$ & $2.5 E+18$ \\
\hline $\begin{array}{c}\text { VB Effective } \\
\text { density of states } \\
\left(1 / \mathrm{cm}^{3}\right)\end{array}$ & $1.8 E+20$ & $1.9 E+18$ & $1.8 E+19$ & $1.8 E+19$ & $1.0 E+18$ & $1.8 E+19$ \\
\hline $\begin{array}{l}\text { Electron thermal } \\
\text { velocity }(\mathrm{cm} / \mathrm{s})\end{array}$ & $1 E+7$ & $1 E+7$ & $1 E+7$ & $1 E+7$ & $1 E+7$ & $1 E+7$ \\
\hline $\begin{array}{l}\text { Hole thermal } \\
\text { velocity }(\mathrm{cm} / \mathrm{s})\end{array}$ & $1 E+7$ & $1 E+7$ & $1 E+7$ & $1 E+7$ & $1 E+7$ & $1 E+7$ \\
\hline $\begin{array}{l}\text { Electron mobility } \\
\left(\mathrm{cm}^{2} / \mathrm{Vs}\right)\end{array}$ & $1.0 E+2$ & 2 & 50 & 32 & $1.6 E+0$ & $2.0 E-4$ \\
\hline $\begin{array}{l}\text { Hole mobility } \\
\left(\mathrm{cm}^{2} / \mathrm{Vs}\right)\end{array}$ & $2.5 E+1$ & 1 & 50 & 3 & $1.6 E+0$ & $2.0 E-4$ \\
\hline $\begin{array}{l}\text { Donor density } N_{D} \\
\left(1 / \mathrm{cm}^{3}\right)\end{array}$ & $1 E+19$ & $1 E+18$ & $1 E+17$ & $1 E+19$ & 0 & 0 \\
\hline $\begin{array}{c}\text { Acceptor density } \\
\mathrm{N}_{\mathrm{A}}\left(1 / \mathrm{cm}^{3}\right)\end{array}$ & 0 & 0 & 0 & 0 & $3.2 E+15$ & $1.0 E+20$ \\
\hline
\end{tabular}


Table 2. Simulation parameters used for back and front contact

\begin{tabular}{ccc}
\hline Parameters & Front contact & Back contact \\
\hline Surface recombination velocity of electrons $(\mathrm{cm} / \mathrm{s})$ & $1.00 E+7$ & $1.00 E+5$ \\
Surface recombination velocity of holes $(\mathrm{cm} / \mathrm{s})$ & $1.00 E+5$ & $1.00 E+7$ \\
Metal work function $(\mathrm{eV})$ & 4.3000 & 5.5000 \\
Majority carrier barrier height relative to $E_{f}(\mathrm{eV})$ & 4.3000 & -0.2000 \\
Majority carrier barrier height relative to $E_{v}(\mathrm{eV}$ & 0.2796 & -0.0912 \\
\hline
\end{tabular}

\section{Results and discussion}

\subsection{Effect of absorber layer thickness on device performance}
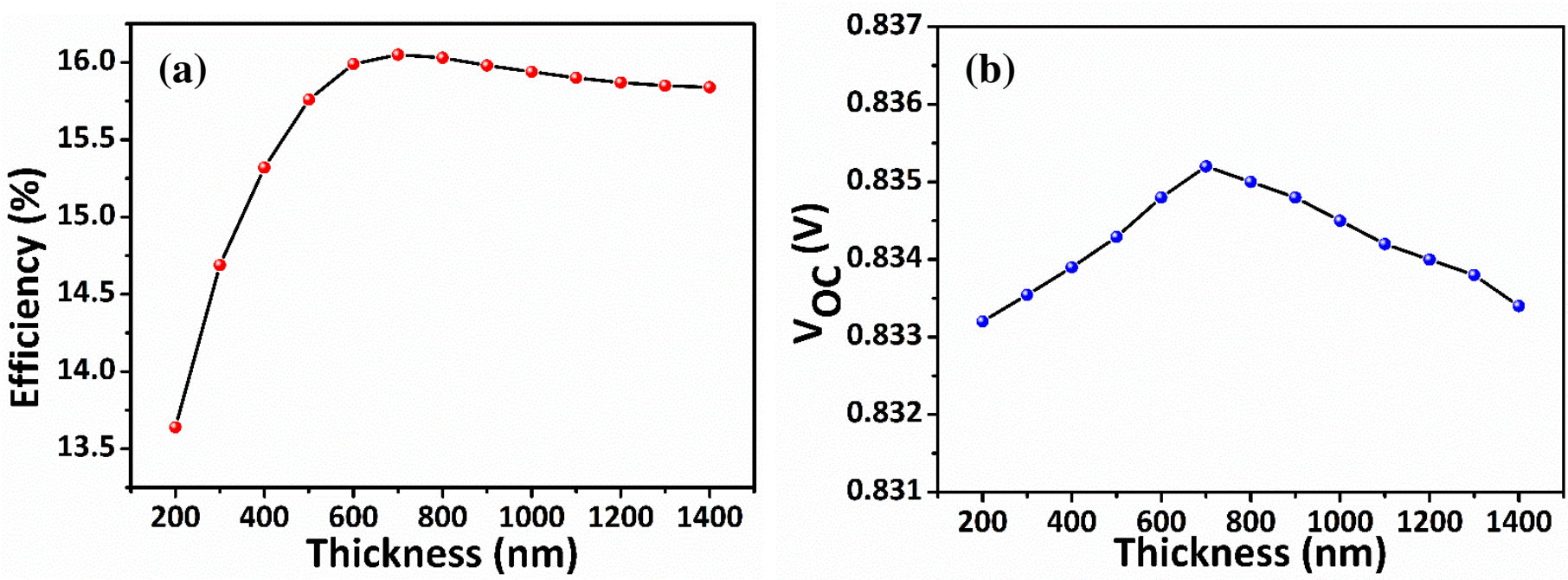

Figure 3. Effect of absorber layer thickness on (a) efficiency and (b) $V_{o c}$

The thickness of the absorber layer plays a vital role in the efficiency of the perovskite solar cell. Response of the solar spectrum by a device can be described as a function of absorber layer thickness. In the present study, the thickness of the absorber layer $\left(\mathrm{CH}_{3} \mathrm{NH}_{3} \mathrm{SnI}_{3}\right)$ has been varied from 100 to 1400 nanometers with spiro-OMeTAD as HTL and ZnO as ETL. The effect of thickness on the efficiency and open circuit potential $\left(\mathrm{V}_{\mathrm{oc}}\right)$ are shown in figure 3 (a) and (b), respectively. The diffusion length of electrons and holes have a direct influence on the absorber layer thickness, i.e. the thickness of the absorber layer should be smaller than the diffusion length of electrons and holes [26]. It ensures that electrons and holes are reaching to the electrodes for the power generation. The light absorption rate increases in consequence of the increment in the layer thickness which leads to higher $\mathrm{V}_{\mathrm{oc}}, \mathrm{J}_{\mathrm{sc}}$ and photo conversion efficiency. On the flip side, the increase in the absorber layer thickness results in the reduction of the back contact recombination current density [27]. Figure 4 (a) and (b) shows the effect 
of absorber layer thickness on the device parameters such as efficiency (PCE) and open circuit voltage $\left(\mathrm{V}_{\mathrm{oc}}\right)$, respectively. It is observed that the PCE and $\mathrm{V}_{\mathrm{oc}}$ increases with increase in the absorber layer thickness in the range of 200 to $700 \mathrm{~nm}$. Beyond $700 \mathrm{~nm}$, it could be seen that a decrement in the PCE as well as the $\mathrm{V}_{\mathrm{oc}}$ as a result of the increase in the carrier diffusion length. Here, the photons are absorbed deep into the absorber layer limiting them from the depletion region. As a consequence, the generated electron hole pair leads to the bulk recombination instead of reaching space charge region during their life span $[28,29]$. The decline in $\mathrm{V}_{\text {oc }}$ after the optimum thickness of the absorber layer can be best explained as the result of the higher recombination rate. Thus, the decline in $\mathrm{V}_{\mathrm{oc}}$ also reflects in the efficiency as well. The $\mathrm{V}_{\text {oc }}$ can be expressed as

$$
V_{o C}=\left(\frac{n k T}{q}\right) \ln \left({\frac{I_{L}}{I_{0}}}_{0}+1\right)
$$

Here, $n$ stands for diode ideality factor and $k T / q$ refers to the thermal voltage. $I_{0}$ and $I_{L}$ are dark and light saturation currents, respectively. A thin absorber layer comes with an advantage of minimal electron hole recombination which possess minimal value of dark saturation current. This might be the possible reason for the gradual increment of $\mathrm{V}_{\mathrm{oc}}$ up to a certain thickness. After the optimum thickness of the perovskite absorber layer, $\mathrm{V}_{\mathrm{oc}}$ decreases due to the increase in dark saturation current. We have also experienced a decrement in the fill factor with increasing thickness which causes more internal power usage [26]. From the simulated results, it is clear that the selection of the absorber layer thickness has to be made according to the diffusion length of the charge carriers. The optimum thickness of the absorber layer should be smaller than the diffusion length in order to make sure the maximum possible efficiency. As per the study, the optimum thickness for the proposed absorber layer is $700 \mathrm{~nm}$ which delivers a PCE of $16.1 \%$. A thicker absorber layer (in between 600 and $800 \mathrm{~nm}$ ) can absorb more number of photons leading to higher efficiency utilizing AM 1.5 G condition. The obtained results are in line with the previous literatures [19]. 


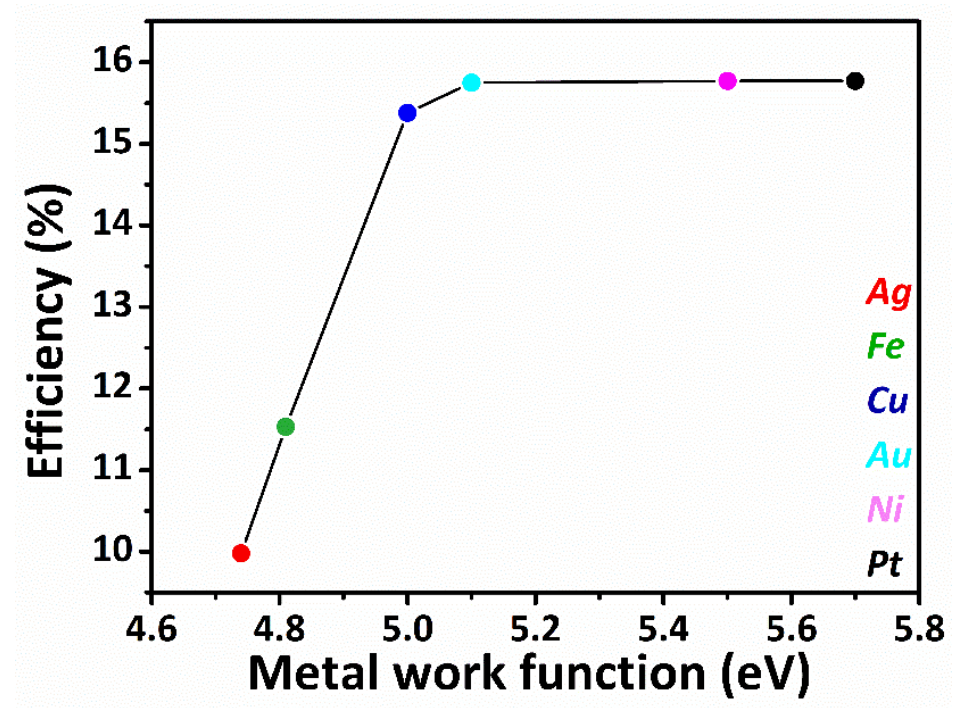

Figure 4. Efficiency as a function of metal work function with varying back contacts

Several back contact materials such as platinum $(\mathrm{Pt})$, nickel $(\mathrm{Ni})$, gold $(\mathrm{Au})$, copper $(\mathrm{Cu})$, iron $(\mathrm{Fe})$, silver $(\mathrm{Ag})$ are employed in the perovskite device architecture. Figure 4 shows the efficiency obtained by devices as a function of metal contact work function. A detailed simulation was employed with different metal contacts and output values are depicted in table 3. The simulated results exhibit an increment in the efficiency for higher work function values. However, the efficiency saturates right after a particular work function value. Most of the carrier barrier height decreases as a result of increased metal work function. Increasing work function also influences the band bending at the metal-semiconductor interface which makes the contact further ohmic [30].

Table 3. Influence of different back contact on the device performance

\begin{tabular}{lcccccc}
\hline & $\mathrm{Ag}$ & $\mathrm{Fe}$ & $\mathrm{Cu}$ & $\mathrm{Au}$ & $\mathrm{Ni}$ & $\mathrm{Pt}$ \\
\hline Metal work & & & & & & \\
function (ev) & 4.74 & 4.81 & 5.00 & 5.10 & 5.50 & 5.70 \\
Efficiency (\%) & 9.98 & 11.53 & 15.38 & 15.75 & 15.77 & 15.77 \\
Fill Factor & 41.33 & 47.09 & 61.2 & 62.56 & 62.61 & 62.61 \\
$\mathrm{~V}_{\mathrm{oc}}(\mathrm{V})$ & 0.8311 & 0.8311 & 0.8322 & 0.8319 & 0.8319 & 0.8319 \\
$\mathrm{~J}_{\mathrm{sc}}\left(\mathrm{mA} \mathrm{cm}^{-2}\right)$ & 29.057 & 29.457 & 30.2032 & 30.2703 & 30.2729 & 30.2729 \\
\hline
\end{tabular}


Lower work function leads to lower efficiency since the electric field near to HTM/back contact interface becomes negative due to the tendency of holes to travel towards electrode [31]. Pt and $\mathrm{Ni}$ shows higher performance as back contacts in the perovskite device architecture. However, the cost effectiveness of Ni makes it as a promising back metal contact for enhanced device performance while comparing to Pt.

\subsection{Effect of density of states (DOS) on the absorber layer}

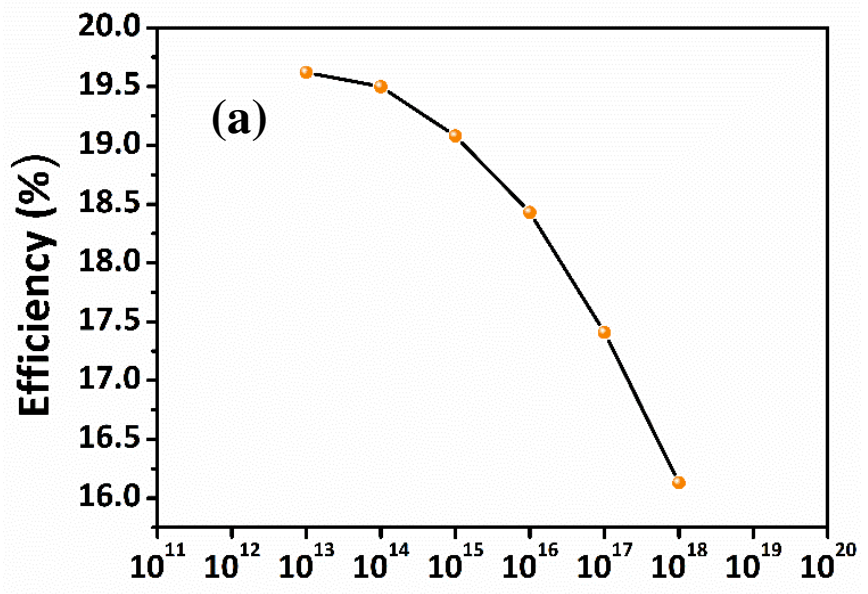

VB Effective density of states $\left(\mathrm{cm}^{-3}\right)$

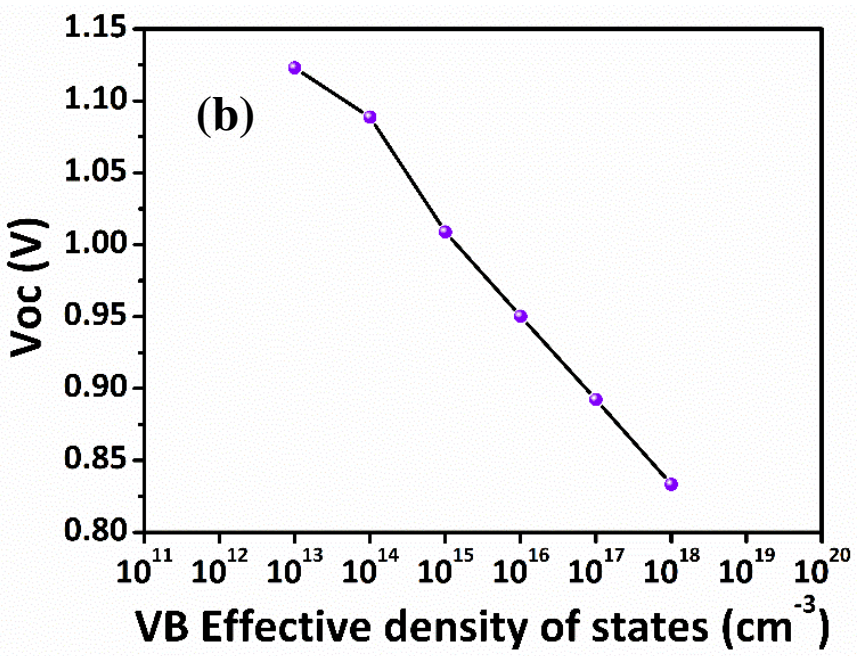

VB Effective density of states $\left(\mathrm{cm}^{-3}\right)$

Figure 5. Effect of density of States on (a) efficiency and (b) $V_{o c}$ of the device.

In order to find out the effect of density of states of the perovskite absorber layer on the efficiency of the device, we have carried out simulation of the device by varying the density of states $\left(N_{V}\right)$ of the absorber layer ranging from $10^{13}$ to $10^{19} \mathrm{~cm}^{-3}$. Figure 5 depicts the efficiency as well as $\mathrm{V}_{\mathrm{oc}}$ of the device as a function of DOS. It is clear from the figure 5 (a) that efficiency decreases with increase in $N v$ of the perovskite absorber layer.

\subsection{Effect of temperature on the device performance}

Working temperature is a crucial factor when it comes to perovskite solar cells. Especially, the parameters such as $\mathrm{J}_{\mathrm{sc}}$ and $\mathrm{V}_{\mathrm{oc}}$ are highly related to its working temperature [32]. An operating temperature of $300 \mathrm{~K}$ was employed for most of the device simulations. In order to probe the effect of temperature on $\mathrm{Pb}$-free perovskite solar cells, working temperature of the device was varied from 300 to $370 \mathrm{~K}$ under constant illumination of $1000 \mathrm{~W} \mathrm{~m}^{-2}$. Figure 6 shows the device parameters as a function of the temperature. 

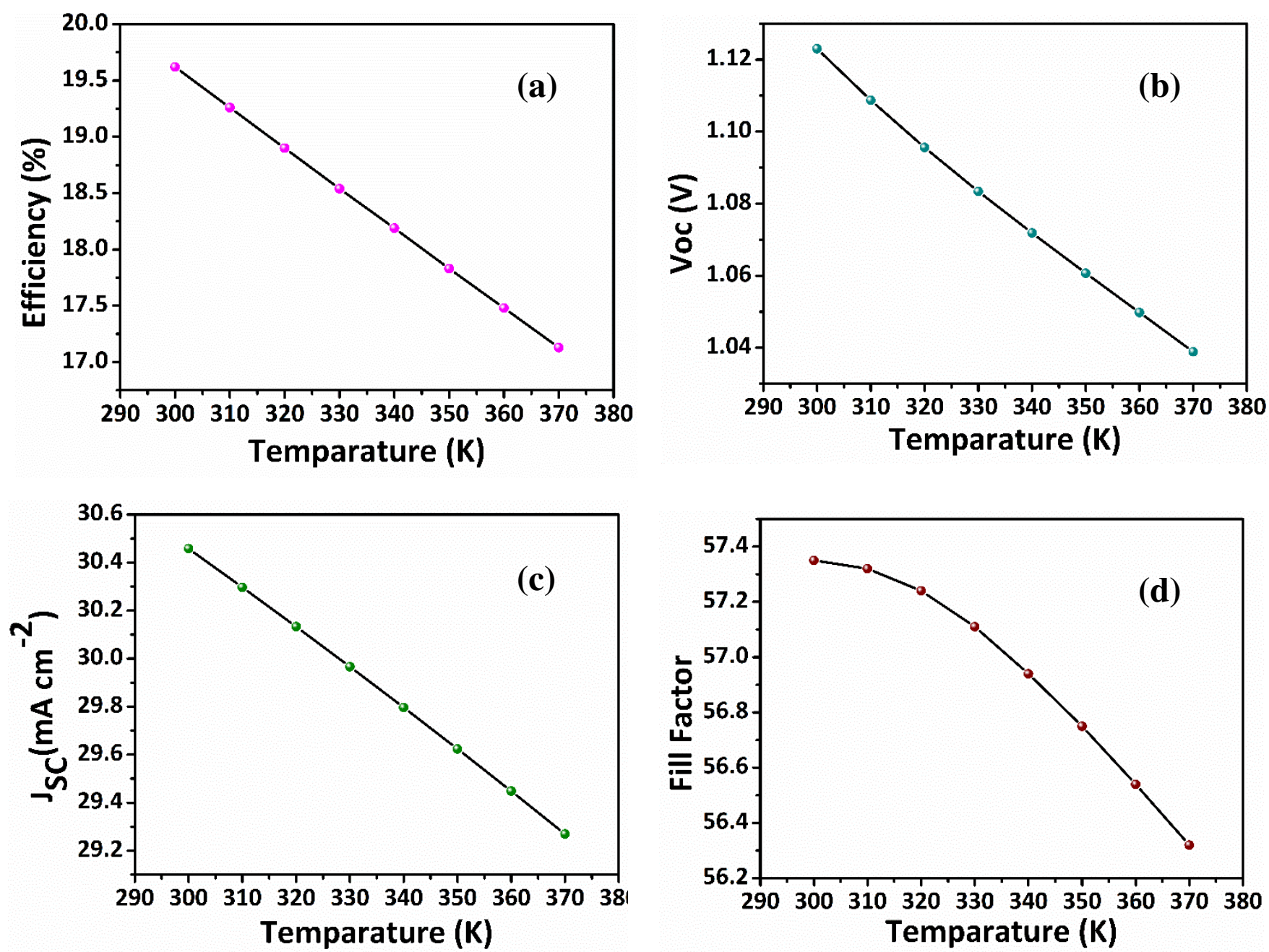

Figure 6. Effect of device temperature on (a) efficiency, (b) $V_{o c}(c) J_{s c}$ and (d) Fill factor

The overall efficiency of the device is significantly decreased as temperature increases. Here $\mathrm{V}_{\mathrm{oc}}$ is a crucial factor that determines the performance of the device. As a result of increase in the device temperature, the reverse saturation current also increases exponentially which leads to a reduction in the $\mathrm{V}_{\text {oc }}$ [33]. The PCE of the device also drastically decreases along with the $\mathrm{V}_{\text {oc. }}$. As temperature increases, device parameters such as band gaps, electron and hole mobility and carrier concentration are affected which results in a lower efficiency of the device $[34,35]$. From the obtained simulation results, we can conclude that the operating temperature exhibits a linear relationship with the device efficiency. Thus, efficiency and the generated power output of the perovskite solar cell is strongly dependent on the working temperature. 
3.5 Effect of absorber defect density on device performance
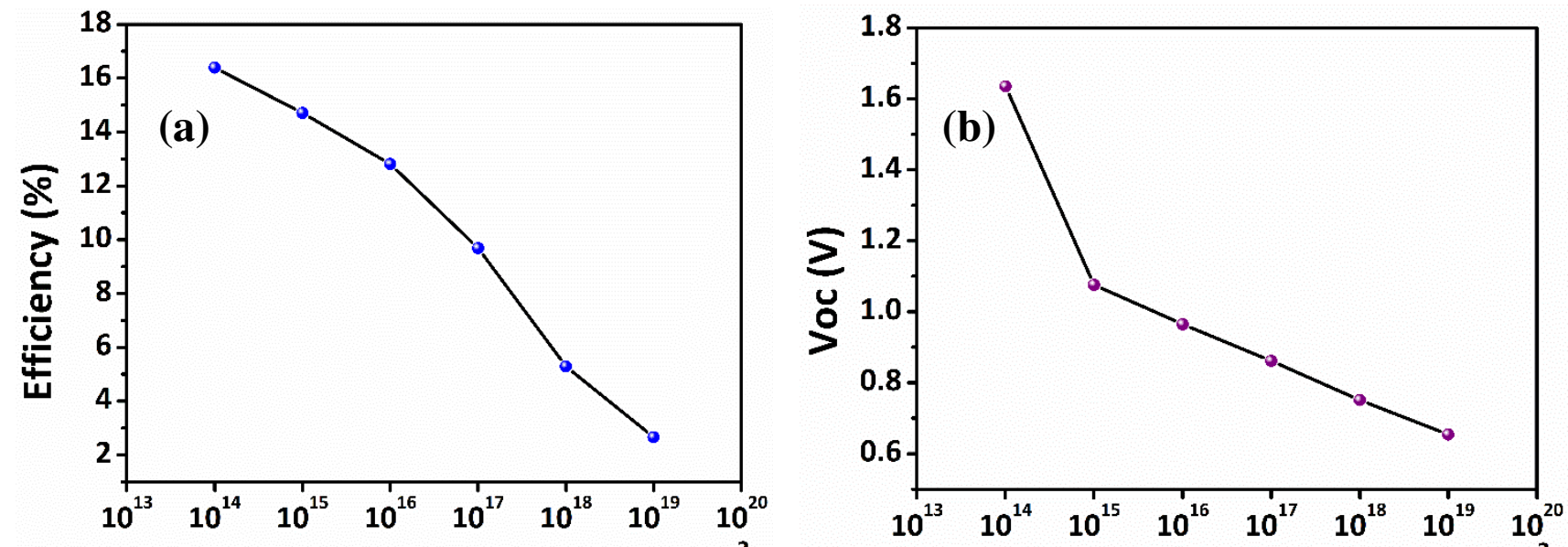

Defect density $(\mathrm{Nt})$ of absorber $\left(\mathrm{cm}^{-3}\right)$
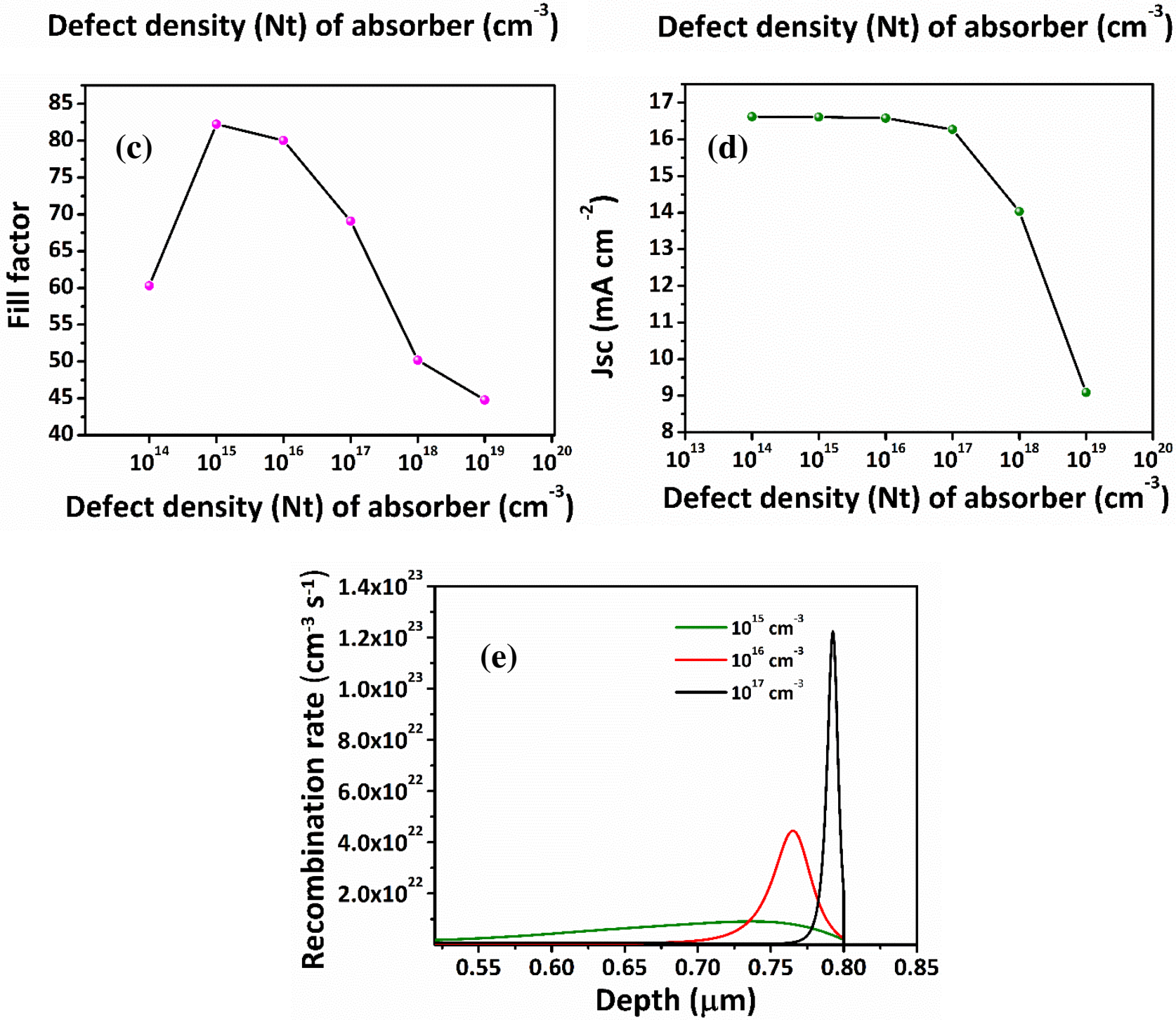

Figure 7. Effect of absorber layer defect density on (a) efficiency, (b) $V_{o c}$, (c) fill factor and (d) $\mathbf{J}_{\mathrm{sc}}(\mathrm{e})$ recombination rate inside perovskite 
The defect on the absorber layer must be well probed in order to obtain maximum efficiency out of the device. The capture cross section of electrons and holes were kept as $10^{-}$ 17 and $10^{-15} \mathrm{~cm}^{2}$, respectively. Gaussian distribution was employed with an energy level 0.70 $\mathrm{eV}[36,37]$. We have varied the absorber defect density from $10^{17}$ to $10^{20} \mathrm{~cm}^{-3}$ to draw a relationship between defect density and efficiency as shown in figure 7. A drastic drop in the efficiency can be observed with the increasing defect density of the absorber layer. The deep energy levels in the band gaps act as Shockley-Read Hall non-radiative recombination centers since the photo-electrons are mainly generated from the absorber layer. As a consequence of these centers, the minority carrier lifetime becomes short and charge recombination dominates over $\mathrm{V}_{\text {oc }}$ [19]. If the defect concentration is exceeding the doping concentration of the absorber layer, the device loses its semi-conductivity and the formation of the proper $\mathrm{p}-\mathrm{n}$ junction is hindered. As a consequence, the device functionality and the efficiency decreases drastically [38]. According to figure 7 (c), we can see a drop in fill factor from $60.31 \%$ to $44.79 \%$ with the increase in defect density from $10^{14}$ to $10^{19} \mathrm{~cm}^{-3}$. A rapid increase in fill factor value can be seen in between $10^{14}$ and $10^{15} \mathrm{~cm}^{-3}$ since the doping density of the perovskite layer was set as $10^{15} \mathrm{~cm}^{-3}$ which is in line with the defect density. Efficiency, $V_{o c}$ and $J_{\mathrm{sc}}$ also exhibits a decrement as defect density increases. Consequently, all device parameters decrease with the increase in defect density values. Thus, in order to get an enhanced output from the device, the absorber layer must have high quality with a few defects. As shown in figure 7e, decreasing the defect density value leads to increase in carrier lifetime and diffusion length. Hence, less recombination is observed which leads to better performance.
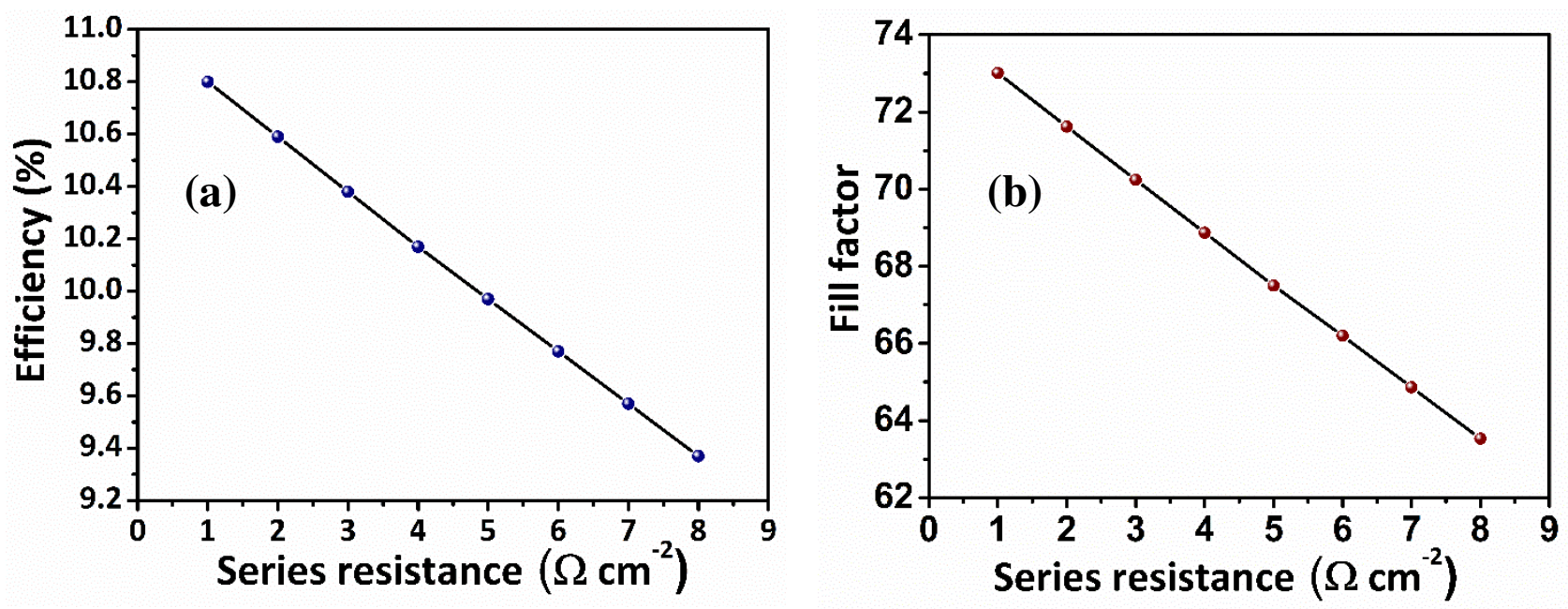

Figure 8. Effect of series resistance on (a) efficiency and (b) fill factor 


\subsection{Effect of change in series resistance on device performance}

Series resistance is one of the important parameter when it comes to the performance of the device. It has direct influence on fill factor and $\mathbf{J}_{\mathrm{sc}}$. Form figure 8 (b), it is evident that the fill factor decreases with the increase in the series resistance. Thus, higher values of series resistance in perovskite solar cells results in poor conversion efficiency. Simulation has been carried out to study the effect of series resistance on PCE and fill factor of perovskite solar cells. The equivalent circuit for basic solar cell is given in figure 2 .

$$
\begin{aligned}
& I_{S C}=I o\left(e^{q V o c / n K T}-1\right) \\
& I_{S c}=I_{L}-I_{O}\left(e^{q V o c / n K T}-1\right)-\frac{V_{o c}+I s c r s}{r s h}
\end{aligned}
$$

Here, equation (5) can be used to analyze the effect of series resistance on device performance [39] where equation (6) stands for the equivalent circuit. Here $I_{L}$ and $I_{s c}$ are light induced current and short circuit current, respectively and $r_{s h}$ stands for shunt resistance. It is evident from the above equation that the value of $I_{s c}$ decreases with an increase in series resistance. This acts as the main reason for the decrement in efficiency as well as fill factor. At lower resistance values, the device exhibits an enhanced performance with a higher fill factor value (Figure 8b). A significant drop in the efficiency of the device can be seen in figure 8a as a function of increase in series resistance. The results obtained from the study are in line with previously reported literatures [40].

\subsection{Optimized device performance}
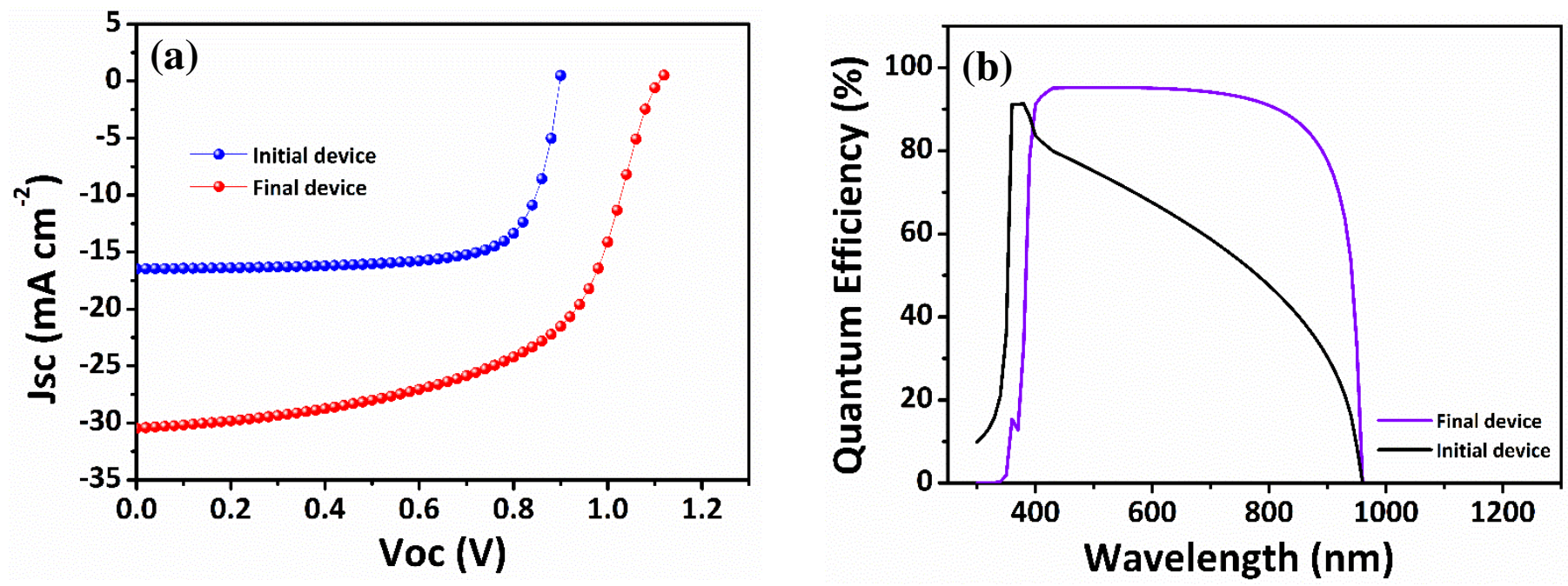

Figure 9. (a) J-V curves and (b) external quantum efficiency of initial and final device based on $\mathrm{ZnO}$ ETL. 
The final device has been simulated employing all the optimized parameters namely thickness of the absorber layer, absorber layer defect density, working temperature, series resistance and metal work function. The performance of the initial and final device is shown in figure 9. The initial and final device showed an efficiency of 11.0 and $19.62 \%$, respectively. The final device delivered a short circuit current density of $30.45 \mathrm{~mA} \mathrm{~cm}{ }^{-2}$ which is 1.8 fold higher than the initial one. A significant increase in $\mathrm{V}_{\mathrm{oc}}$ can be seen in the final device compared to the initial one. A decrement in fill factor has occurred from 74 to 58 in the case of final device which might be attributed to the increase in short circuit current density. The $V_{o c}$ obtained for the initial and final devices are 0.8985 and $1.1089 \mathrm{~V}$, respectively. Around $20 \%$ increment in $\mathrm{V}_{\text {oc }}$ was observed for final device while comparing to the initial device. The final optimized device exhibited $56.3 \%$ higher efficiency than the initial one which also shows the potential ability of tin-based perovskite solar cell compared to its $\mathrm{Pb}$-based counterparts. Figure 9 (b) shows the external quantum efficiency of the initial and final devices. The final device exhibits desirable output throughout the visible as well as the near infrared region compared to the initial device.

\subsection{Performance of different ETL materials in the optimized device architecture}

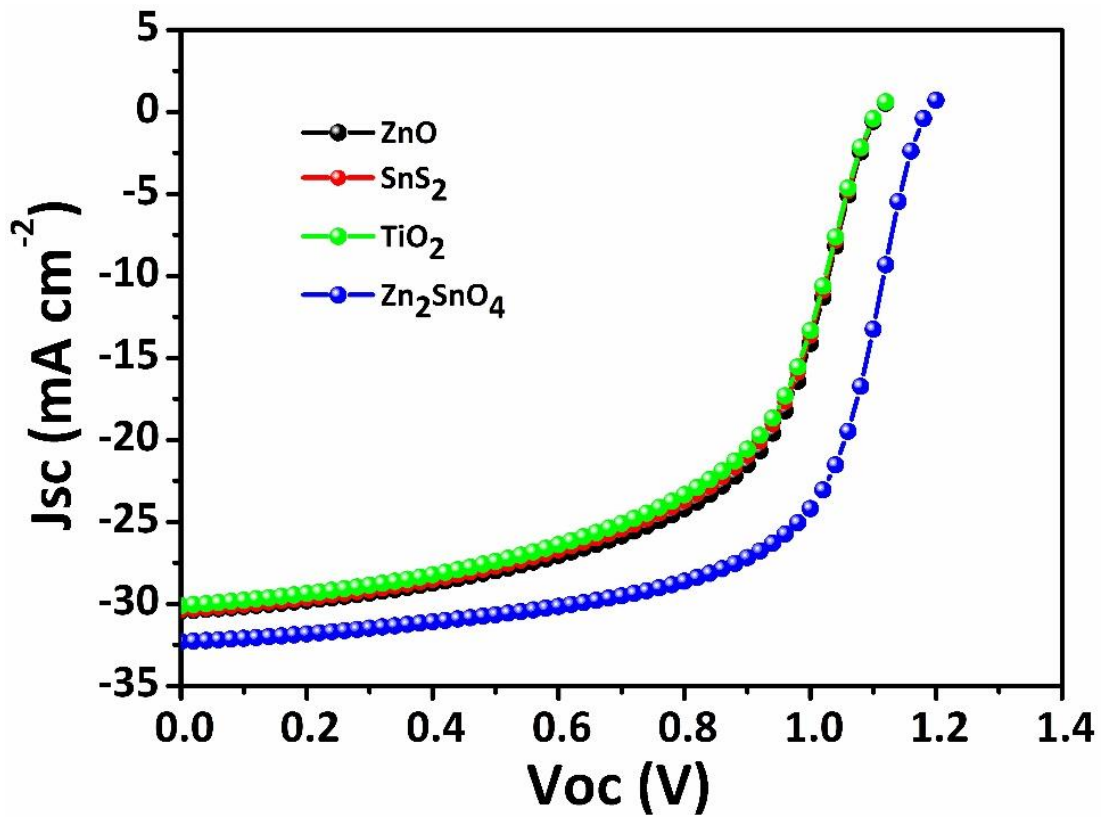

Figure 10. (a) J-V curves for different ETL materials.

Different ETL materials were introduced into the device architecture after optimizing the device parameters such as thickness and defect density of the absorber layer, device temperature and resistance, recombination rate, etc. with $\mathrm{ZnO}$ as ETL. We were able to identify $\mathrm{Zn}_{2} \mathrm{SnO}_{4}$ as a viable and effective ETL material for lead free perovskite solar cell among the 
different ETL candidates implemented such as $\mathrm{SnS}_{2}, \mathrm{ZnO}, \mathrm{TiO}_{2} . \mathrm{Zn}_{2} \mathrm{SnO}_{4}$ based device exhibited an efficiency of $24.73 \%$ which is comparable with previous works [41] with an enhanced $\mathrm{V}_{\mathrm{oc}}$ of $1.1857 \mathrm{~V}$. The detailed performance of all ETL candidates has depicted in table 4.

Table 4. Device performance with different ETL materials.

\begin{tabular}{ccccc}
\hline ETL & $\mathrm{V}_{\text {oc }}(\mathrm{V})$ & $\mathrm{J}_{\mathrm{sc}}\left(\mathrm{mA} \mathrm{cm}^{-2}\right)$ & FF & PCE (\%) \\
\hline $\mathrm{Zn}_{2} \mathrm{SnO}_{4}$ & 1.1857 & 32.301538 & 64.58 & 24.73 \\
$\mathrm{ZnO}$ & 1.1089 & 30.458087 & 58.08 & 19.62 \\
$\mathrm{SnS}_{2}$ & 1.1075 & 30.398688 & 56.96 & 19.18 \\
$\mathrm{TiO}_{2}$ & 1.1066 & 30.112588 & 56.56 & 18.85 \\
\hline
\end{tabular}

\section{Conclusion}

$\mathrm{Pb}$-free tin-based $\left(\mathrm{CH}_{3} \mathrm{NH}_{3} \mathrm{SnI}_{3}\right)$ perovskite solar cell have been designed and constructed using SCAPS. The designed model was verified by comparing the parameters with the reported literatures. Different absorber parameters along with the working conditions of the device have been exclusively studied. According to the obtained simulation results, absorber thickness was a crucial factor for the performance of the device. Increasing the absorber layer thickness also influenced the $\mathrm{J}_{\mathrm{sc}}$ value. An absorber layer thickness of $700 \mathrm{~nm}$ was optimal for delivering an efficiency of $19.68 \%$. Further, the bulk defect also degraded the overall performance of the device. When the bulk defect of the absorber layer was increased, all device parameters tended to decrease drastically due to the higher recombination rate and subsequent increase in the series resistance. The rise in series resistance as well as working temperature degraded the device performance. $\mathrm{Zn}_{2} \mathrm{SnO}_{4}$ based ETL device delivered a maximum efficiency of $24.73 \%$ among other proposed ETLs. The present study proposed a planar device architecture $\left(\mathrm{Zn}_{2} \mathrm{SnO}_{4} / \mathrm{CH}_{3} \mathrm{NH}_{3} \mathrm{SnI}_{3} /\right.$ Spiro-MeOTAD) for tin-based perovskite solar cells and it can also be utilized to investigate the effect of device parameters on other perovskite based solar cells. Further, extensive experimental studies are required for the investigation of the proposed tin-based perovskite solar cell in order to completely replace the lead-based analogues since lead toxicity is a serious threat to our eco system. 


\section{Conflict of interest}

Authors declare no competing conflict of interest.

\section{Acknowledgements}

We acknowledge Dr. Marc Burgelman, University of Gent, Belgium, for providing the free access to SCAPS-1D.

\section{References}

1. Burschka, J., et al., Sequential deposition as a route to high-performance perovskitesensitized solar cells. Nature, 2013. 499(7458): p. 316-319.

2. $\quad$ Green, M.A., et al., Solar cell efficiency tables (Version 53). Progress in Photovoltaics: Research and Applications, 2019. 27(1): p. 3-12.

3. Kooijman, A., L.A. Muscarella, and R.M. Williams, Perovskite Thin Film Materials Stabilized and Enhanced by Zinc(II) Doping. Applied Sciences, 2019. 9(8).

4. Liu, M., M.B. Johnston, and H.J. Snaith, Efficient planar heterojunction perovskite solar cells by vapour deposition. Nature, 2013. 501(7467): p. 395-398.

5. Rehan, S., et al., Carbon-Impurity Affected Depth Elemental Distribution in SolutionProcessed Inorganic Thin Films for Solar Cell Application. ACS applied materials \&amp; interfaces, 2016. 8(8): p. 5261-5272.

6. $\quad$ Shin, S.S., et al., Colloidally prepared La-doped BaSnO\&lt;sub\&gt;3\&lt;/sub\&gt; electrodes for efficient, photostable perovskite solar cells. Science, 2017. 356(6334): p. 167.

7. Zhao, Z., et al., Metal Halide Perovskite Materials for Solar Cells with Long-Term Stability. Advanced Energy Materials, 2019. 9(3): p. 1802671.

8. Xiao, Z., et al., Searching for promising new perovskite-based photovoltaic absorbers: the importance of electronic dimensionality. Materials Horizons, 2017. 4(2): p. 206216.

9. Xing, G., et al., Long-range balanced electron- and hole-transport lengths in organicinorganic CH3NH3PbI3. Science, 2013. 342(6156): p. 344-7.

10. Seo, J., J.H. Noh, and S.I. Seok, Rational Strategies for Efficient Perovskite Solar Cells. Accounts of Chemical Research, 2016. 49(3): p. 562-572.

11. Ke, W. and M.G. Kanatzidis, Prospects for low-toxicity lead-free perovskite solar cells. Nature Communications, 2019. 10(1): p. 965.

12. Jena, A.K., A. Kulkarni, and T. Miyasaka, Halide Perovskite Photovoltaics: Background, Status, and Future Prospects. Chemical Reviews, 2019. 119(5): p. 30363103.

13. Arunkumar Prabhakaran, S., et al., Tin as an Emerging Surrogate for Lead-free Perovskite Solar Cells. Nanoscience \& Nanotechnology-Asia, 2020. 10: p. 1-14.

14. Lyu, M., et al., Addressing Toxicity of Lead: Progress and Applications of Low-Toxic Metal Halide Perovskites and Their Derivatives. Advanced Energy Materials, 2017. 7(15): p. 1602512.

15. Shockley, W. and H.J. Queisser, Detailed Balance Limit of Efficiency of p-n Junction Solar Cells. Journal of Applied Physics, 1961. 32(3): p. 510-519.

16. Konstantakou, M. and T. Stergiopoulos, A critical review on tin halide perovskite solar cells. Journal of Materials Chemistry A, 2017. 5(23): p. 11518-11549. 
17. Burgelman, M., SCAPS manual, 2013. 2013, Elis, Gent university.

18. Abdelaziz, S., et al., Investigating the performance of formamidinium tin-based perovskite solar cell by SCAPS device simulation. Optical Materials, 2020. 101: p. 109738.

19. Devi, N., et al., Numerical simulations of perovskite thin-film solar cells using a CdS hole blocking layer. Journal of Vacuum Science \& Technology B, 2018. 36(4): p. $04 \mathrm{G} 105$.

20. Hima, A. and N. Lakhdar, Enhancement of efficiency and stability of CH3NH3GeI3 solar cells with CuSbS2. Optical Materials, 2020. 99: p. 109607.

21. Haider, S.Z., H. Anwar, and M. Wang, A comprehensive device modelling of perovskite solar cell with inorganic copper iodide as hole transport material. Semiconductor Science and Technology, 2018. 33(3): p. 035001.

22. Du, H.-J., W.-C. Wang, and J.-Z. Zhu, Device simulation of lead-free CH 3 NH 3 SnI 3 perovskite solar cells with high efficiency. Chinese Physics B, 2016. 25(10): p. 108802.

23. Umari, P., E. Mosconi, and F. De Angelis, Relativistic GW calculations on CH3NH3PbI3 and CH3NH3SnI3 Perovskites for Solar Cell Applications. Scientific Reports, 2014. 4(1): p. 4467.

24. Hossain, M.I., F.H. Alharbi, and N. Tabet, Copper oxide as inorganic hole transport material for lead halide perovskite based solar cells. Solar Energy, 2015. 120: p. 370380.

25. Mahbub, R., et al. Simulation of CZTS thin film solar cell for different buffer layers for high efficiency performance. 2017.

26. Tan, K., et al., Controllable design of solid-state perovskite solar cells by SCAPS device simulation. Solid-State Electronics, 2016. 126: p. 75-80.

27. Khoshsirat, N., et al., Analysis of absorber layer properties effect on CIGS solar cell performance using SCAPS. Optik, 2015. 126(7): p. 681-686.

28. Saparov, B., et al., Thin-Film Preparation and Characterization of Cs3Sb2I9: A LeadFree Layered Perovskite Semiconductor. Chemistry of Materials, 2015. 27(16): p. 5622-5632.

29. Yang, Y. and J. You, Make perovskite solar cells stable. Nature, 2017. 544(7649): p. 155-156.

30. Liu, P., et al., Cadmium sulfide nanowires for the window semiconductor layer in thin film CdS-CdTe solar cells. Nanotechnology, 2011. 22(14): p. 145304.

31. Behrouznejad, F., et al., A study on utilizing different metals as the back contact of CH3NH3PbI3 perovskite solar cells. Journal of Materials Chemistry A, 2016. 4(35): p. 13488-13498.

32. Rahul, et al., New class of lead free perovskite material for low-cost solar cell application. Materials Research Bulletin, 2018. 97: p. 572-577.

33. Fahrenbruch, A.L. and R.H. Bube, CHAPTER 1 - SURVEY OF BASIC CONCEPTS, in Fundamentals of Solar Cells, A.L. Fahrenbruch and R.H. Bube, Editors. 1983, Academic Press. p. 1-25.

34. Nakada, T. and M. Mizutani, $18 \%$ Efficiency Cd-Free Cu(In, Ga)Se2 Thin-Film Solar Cells Fabricated Using Chemical Bath Deposition (CBD)-ZnS Buffer Layers. Japanese Journal of Applied Physics, 2002. 41(Part 2, No. 2B): p. L165-L167.

35. Chelvanathan, P., M.I. Hossain, and N. Amin, Performance analysis of copperindium-gallium-diselenide (CIGS) solar cells with various buffer layers by SCAPS. Current Applied Physics, 2010. 10(3, Supplement): p. S387-S391. 
36. Yin, W.-J., T. Shi, and Y. Yan, Unique Properties of Halide Perovskites as Possible Origins of the Superior Solar Cell Performance. Advanced Materials, 2014. 26(27): p. 4653-4658.

37. De Wolf, S., et al., Organometallic Halide Perovskites: Sharp Optical Absorption Edge and Its Relation to Photovoltaic Performance. The Journal of Physical Chemistry Letters, 2014. 5(6): p. 1035-1039.

38. Zhu, L., G. Shao, and J.K. Luo, Numerical study of metal oxide hetero-junction solar cells with defects and interface states. Semiconductor Science and Technology, 2013. 28(5): p. 055004.

39. Heriche, H., Z. Rouabah, and N. Bouarissa, New ultra thin CIGS structure solar cells using SCAPS simulation program. International Journal of Hydrogen Energy, 2017. 42(15): p. 9524-9532.

40. Jeon, N.J., et al., Compositional engineering of perovskite materials for highperformance solar cells. Nature, 2015. 517(7535): p. 476-480.

41. Yasin, S., T. Al Zoubi, and M. Moustafa, Design and simulation of high efficiency leadfree heterostructure perovskite solar cell using SCAPS-1D. Optik, 2021. 229: p. 166258. 